\title{
Venturia ribis: a new species of ascomycete
}

\author{
A. SIVANESAN
}

SIVANESAN, A. 1985: Venturia ribis: a new species of ascomycete. - Karstenia 25: $50-52$.

Venturia ribis Sivanesan, sp.nov. on Ribes alpinum L. from Finland is described and illustrated. No species of Venturia has been reported on Ribes so far. It is closely allied to the Venturia species in which the ascospores are septate just above the middle. V. aesculi (H. Sydow) Sivan., V. corni E. Müller, V. frangulae Krieger and $V$. pruni Barr have similarly septate ascospores whose size also lie within close range of that of $V$. ribis. The differences between these species and that of $V$. ribis are given.

A. Sivanesan, Commonwealth Mycological Institute, Ferry Lane, Kew, Surrey TW9 $3 A F$, United Kingdom

\section{Introduction}

The species described here was collected by $\mathrm{Mr}$. Unto Söderholm (Tampere, Finland), who was kind enough to let me describe it. In the monograph of Venturia by Sivanesan (1977) no species has been reported on Ribes. It was compared with closely related species like $V$. aesculi (H. Sydow) Sivan., $V$. corni E. Müller, $V$. frangulae Krieger and $V$. pruni Barr. It differs from $V$. aesculi, $V$. corni and $V$. pruni in the setose ascostroma and from $V$. frangulae in the shape of asci and in the shorter setae. The ascospores in $V$. aesculi are smooth to verrucose and in $V$. corni they are much wider. The asci in $V$. pruni are much smaller than in $V$. ribis. The differences between these species and that of $V$. ribis are given below (Table 1).

\section{Venturia ribis Sivanesan, sp.nov.}

- Figs. $1-5$

Ascostromata immersa, subepidermalia, dispersa, amphigena, plerumque hypophylla, globosa, 60-85 $\mu \mathrm{m}$ alta, 65-83 $\mu \mathrm{m}$ in diam, ostiolo papilliformi setulis aculeatis ornato. Setae atrobrunneae, crassitunicatae, aseptatae, 30-50 $\mathrm{mm}$ longae, usque $4.5 \mu \mathrm{m}$ crassae. Muri ascostromati 6.5-8 4 m crassi, e cellulis pseudoparenchymati, crassitunicati, stratis 2-3 textura angularum formans. Asci obclavati cylindrici, brevi pedicellati, bitunicati, 38-50 $\times 6-10 \mu \mathrm{m}$. Ascosporae supra medium uniseptatae, constrictae, oblongae, olivaceae, deorsum biseriatae sursum uniseriatae in asco, subtiliter verruculosae, cellula superiore leviter latiore, 9-10.5 × 3-3.5 $\mu \mathrm{m}$. Pseudoparaphyses filiformes, hyalinae, ramosae, septatae.

Fig. 1. Venturia ribis. - a) ascus, b) pseudoparaphyses, c) ascospores.

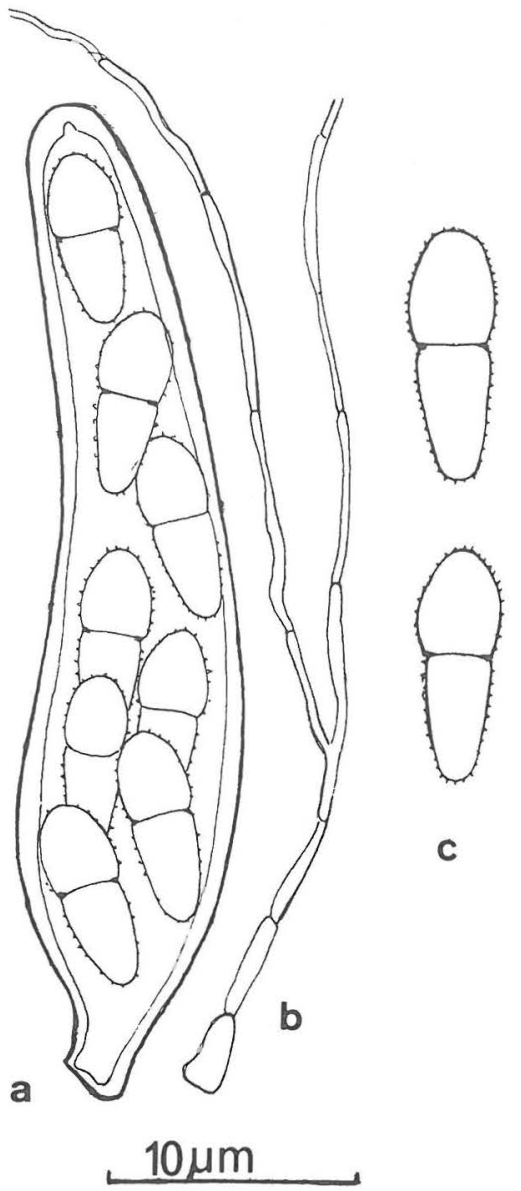



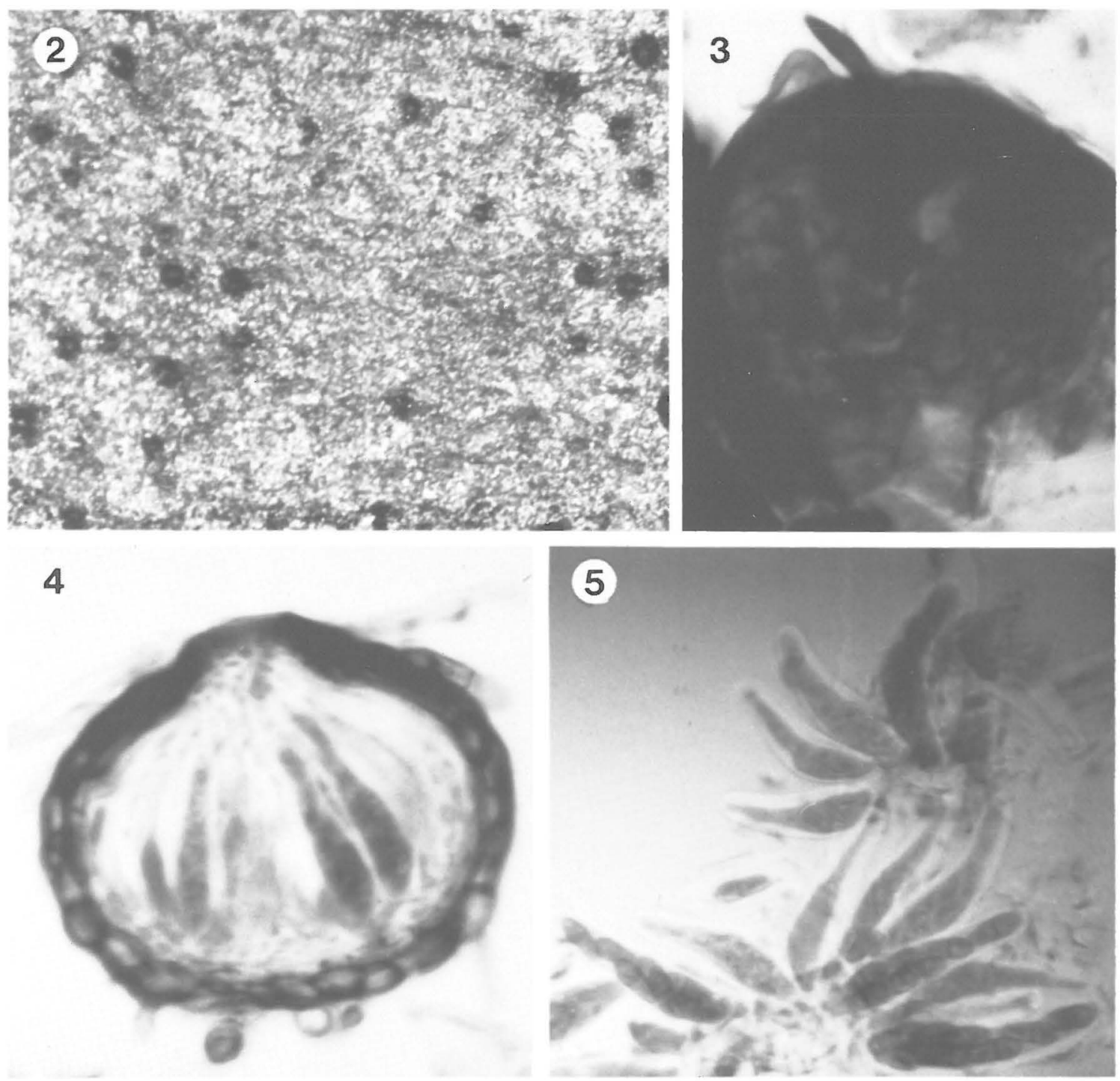

Figs. 2-5. Venturia ribis. -2 : Ascostromata on leaf, $\times 50 .-3$ : Ascostroma with setae, $\times$ 650. -4 : Vertical section of ascostroma, $\times 650$. - 5: Asci and ascospores, $\times 650$.

Typus: Finland. Tavastia australis: Kangasala, Vihtinen, on dead leaves of Ribes alpinum L., 20 May 1984 Unto Söderholm 1064 (IMI 286723) holotypus.

Ascostromata immersed, subepidermal, scattered, amphigenous, mostly hypophyllous, globose, $60-85$ $\mu \mathrm{m}$ high, $65-83 \mu \mathrm{m}$ in diam, with a protruding, often setose, papillate ostiole. Setae dark brown, thick-walled, aseptate, $30-50 \mu \mathrm{m}$ long, up to 4.5 $\mu \mathrm{m}$ thick. The ascostromatal wall, 6.5-8 $\mu \mathrm{m}$ thick, is composed of thick-walled, pseudoparenchymatous cells forming a textura angularis of $2-3$ layers. Asci obclavate cylindric, short-stalked, 8-spored, bitunicate, $38-50 \times 6-10 \mu \mathrm{m}$. Ascospores 1-septate just above the middle, constricted at the septum, oblong, olive green, biseriate below and uniseriate above in the ascus, upper cell slightly wider than the lower cell, finely verruculose, $9-10.5 \times 3-3.5 \mu \mathrm{m}$. Pseudoparaphyses filiform, hyaline, branched, septate. Anamorph not observed.

Other specimen examined: Finland. Tavastia australis: Kangasala, Vihtinen, on dead leaves of Ribes alpinum, 5 June 1983 Söderholm 926 (IMI 279169). 
Table 1. Comparison of closely related Venturia species.

\begin{tabular}{|c|c|c|c|}
\hline Species & Ascostroma & Asci & Ascospores \\
\hline V. aesculi & non setose & $\begin{array}{l}\text { broadly cylindrical, } 30-40 \times \\
5-9 \mu \mathrm{m}\end{array}$ & $\begin{array}{l}\text { smooth to verrucose, } 8-9 \times \\
2.5-3.5 \mu \mathrm{m}\end{array}$ \\
\hline V. corni & non setose & cylindrical, $38-45 \times 8-10 \mu \mathrm{m}$ & smooth, $10-11 \times 5-6 \mu \mathrm{m}$ \\
\hline V. frangulae & $\begin{array}{l}\text { setose, setae up to } 200 \\
\mu \mathrm{m} \text { long }\end{array}$ & $\begin{array}{l}\text { cylindrical to cylindric clavate, } \\
35-50 \times 6-10 \mu \mathrm{m}\end{array}$ & smooth, 7-10 $\times 2-4 \mu \mathrm{m}$ \\
\hline V. pruni & non setose & cylindrical, $25-30 \times 6-9 \mu \mathrm{m}$ & smooth, $9-10 \times 3-3.5 \mu \mathrm{m}$ \\
\hline V. ribis & $\begin{array}{l}\text { often setose, setae } 30-50 \\
\mu \text { m long }\end{array}$ & $\begin{array}{l}\text { obclavate cylindric, } 38-50 \times \\
6-10 \mu \mathrm{m}\end{array}$ & $\begin{array}{l}\text { finely verruculose, } 9-10.5 \times 3- \\
3.5 \mu \mathrm{m}\end{array}$ \\
\hline
\end{tabular}

\section{Reference}

Sivanesan, A. 1977: The taxonomy and pathology of Venturia species. - Biblioth. Mycol. 59: 1-138.

Accepted for publication on July 5, 1984 